JOURNAL of

MAINE MEDICAL CENTER Journal of Maine Medical Center

\title{
Total Body Photography and Sequential Digital Dermoscopy Imaging for Melanoma Surveillance in Patients Starting Natalizumab for Multiple Sclerosis
}

Tyler Nussinow BA

Maine Medical Partners Dermatology

Et al.

Follow this and additional works at: https://knowledgeconnection.mainehealth.org/jmmc

Part of the Dermatology Commons, and the Neurology Commons

\section{Recommended Citation}

Nussinow, Tyler BA; Robinson, Amanda NP; Beretich, Biljana MD; Stevens, Kathryn NP; and Seiverling, Elizabeth MD (2021) "Total Body Photography and Sequential Digital Dermoscopy Imaging for Melanoma Surveillance in Patients Starting Natalizumab for Multiple Sclerosis," Journal of Maine Medical Center.

Vol. 3 : Iss. 2 , Article 10.

Available at: https://knowledgeconnection.mainehealth.org/jmmc/vol3/iss2/10 https://doi.org/10.46804/ 2641-2225.1083

The views and thoughts expressed in this manuscript belong solely to the author[s] and do not reflect the opinions of the Journal of Maine Medical Center or MaineHealth.

This Innovation Highlight is brought to you for free and open access by Maine Medical Center Department of Medical Education. It has been accepted for inclusion in the Journal of Maine Medical Center by an authorized editor of the MaineHealth Knowledge Connection. For more information, please contact Dina McKelvy mckeld1@mmc.org.

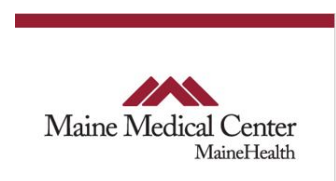


Total Body Photography and Sequential Digital Dermoscopy Imaging for Melanoma Surveillance in Patients Starting Natalizumab for Multiple Sclerosis

\section{Authors}

Tyler Nussinow BA, Amanda Robinson NP, Biljana Beretich MD, Kathryn Stevens NP, and Elizabeth Seiverling MD 


\title{
Total Body Photography and Sequential Digital Dermoscopy Imaging for Melanoma Surveillance in Patients Starting Natalizumab for Multiple Sclerosis
}

\author{
Tyler Nussinow, BA, ${ }^{1}$ Amanda Robinson, NP, ${ }^{1}$ Biljana Beretich, MD, ${ }^{2}$ Kathryn Stevens, NP, ${ }^{1}$ Elizabeth \\ Seiverling, $\mathrm{MD}^{1}$ \\ ${ }^{1}$ Maine Medical Partners Dermatology, Maine Medical Center, Portland ME, ${ }^{2}$ Maine Medical Partners Neurology, Maine \\ Medical Center, Portland ME
}

\begin{abstract}
Introduction: Natalizumab is an integrin receptor antagonist that has been approved by the Food and Drug Administration to treat multiple sclerosis and Crohn's disease. The drug has been linked to an increased risk of melanoma. This brief report highlights an innovative clinical approach for monitoring the skin of patients prescribed natalizumab.
\end{abstract}

Methods: $\quad$ We include 2 cases from our skin oncology clinic and a literature review on the incidence of melanoma in patients prescribed natalizumab between 2004 and 2019.

Results: $\quad$ In addition to our 2 cases, we found 193 reports of patients with melanoma who were prescribed natalizumab. We propose an innovative and proactive approach using total body photography and sequential digital dermoscopy imaging before starting and while treating patients with natalizumab.

Discussion: Given the mechanism of action of natalizumab, many of the melanomas diagnosed likely arose from preexisting melanocytic nevi. Using total body photography before starting this high-risk medication and then sequential digital dermoscopy imaging will increase a dermatologist's ability to recognize new and preexisting skin lesions that have evolved since the patient began taking natalizumab.

Conclusions: Using the latest non-invasive technology to detect skin cancer supports systematic and objective monitoring of changing melanocytic growths in patients prescribed natalizumab, resulting in earlier detection of melanoma and greater cure rates.

Keywords: $\quad$ total body photography, dermoscopy, melanoma, multiple sclerosis, natalizumab, Crohn's disease

$\mathrm{N}$ atalizumab (Tysabri) is a recombinant, humanized monoclonal antibody that binds to $\alpha 4 \beta 1$-integrin and blocks its interaction with vascular cell adhesion molecule-1. As a result, leukocyte migration into brain tissue is inhibited, reducing inflammation and preventing the formation of lesions. ${ }^{1}$ Natalizumab is approved by the Food and Drug Administration (FDA) to treat multiple sclerosis (MS) and Crohn's disease. Typically, this drug is given via a 1-hour infusion every 4 weeks. ${ }^{2}$ On average, patients receive natalizumab

Correspondence: Elizabeth V. Seiverling MD

Maine Medical Partners Dermatology, Maine Medical Center 265 Western Ave, Suite1

South Portland, ME 04106

ESeiverlin@mmc.org treatments over 30 infusions, or approximately 2.5 years. ${ }^{3}$

Natalizumab comes with a black box warning highlighting the increased risk of progressive multifocal leukoencephalopathy, a viral infection of the brain that can lead to death. ${ }^{2}$ Yet, the FDA prescribing information does not mention that numerous reports correlated natalizumab and the development of melanoma, a potentially deadly skin cancer if not caught early. ${ }^{4,5,6}$ In one study from Italy, patients receiving natalizumab for MS were 3 times more likely to develop melanoma than the general population. ${ }^{7}$ It is still unclear how natalizumab promotes melanoma development. A recent study by Carbone et al did not find a direct link between 
natalizumab treatment and the development of cutaneous melanoma. ${ }^{8}$ Rather, natalizumab may indirectly favor melanoma progression by impairing the function of natural killer cells, therefore modifying the tumor microenvironment toward immune suppression and proangiogenesis. ${ }^{3}$

This brief report highlights an innovative clinical approach for monitoring the skin in patients prescribed natalizumab.

\section{METHODS}

Maine Medical Partners Dermatology has a dedicated skin oncology clinic with cutting-edge technology (not widely available) to support their care of patients prescribed high-risk medications or who have a history of melanoma or multiple nonmelanoma skin cancers. One type of this technology is total body photography (TBP). High-quality, whole-body images of the patient's pigmented skin lesions are taken via FotoFinder, a computerized system that maps moles. This technology also allows for high-resolution digital dermoscopy with up to $140 \times$ magnification. ${ }^{9}$ Dermoscopy supports in vivo evaluation of colors and structures of the epidermis and parts of the dermis not visible to the naked eye. ${ }^{10}$ Sequential digital dermoscopy imaging (SDDI) offers a time-lapse comparative of pigmented skin lesions at different time intervals, supporting detection of changes as subtle as 1/10 millimeter. ${ }^{11}$ Another type of cutting-edge technology is reflectance confocal microscopy (RCM). This noninvasive technique supports analysis of growths at the cellular level in vivo. RCM and TBP have been shown to aid in melanoma detection.

We include 2 case reports from our skin oncology clinic. Formal written consent was obtained. We also reviewed the literature for the incidence of melanoma in patients prescribed natalizumab. Information on natalizumab-associated melanomas was identified by examining peer-reviewed literature in PubMed from 2004 to 2019 using the keywords "natalizumab" and "melanoma." Articles reviewed were limited to the English language.

Based on our findings of numerous reports describing natalizumab-associated melanomas, we partnered with the Center for Comprehensive MS Care at Maine Medical Partners Neurology to develop an innovative management strategy for monitoring skin cancer. This center cares for https://knowledgeconnection.mainehealth.org/jmmc/vol3/iss $2 / 10$ DOI: $10.46804 / 2641-2225.1083$ approximately 1250 patients with MS and 280 patients with other demyelinating diseases. In 2020, approximately 76 patients at the clinic were treated with natalizumab.

\section{RESULTS}

\section{Case reports}

Case 1: A 35-year-old female with no prior history of skin cancer was given natalizumab for MS for approximately 3 years before she presented with an enlarging pigmented growth on the lateral aspect of her right thigh (Figure 1A). The growth had been present since her childhood and became darker and larger shortly after she started treatment with natalizumab. Dermoscopy revealed a disorganized pattern within a melanocytic growth. Also present were shiny white structures, a blue-gray veil, and dotted vessels (Figure 1B). Due to concern for melanoma, she underwent a saucerization skin biopsy for depth and breadth under local anesthesia. The pathology report showed a superficial spreading malignant melanoma, stage 1b (0.8 mm, no ulceration), with peripheral and deep margins free of involvement. Her treatment with natalizumab was stopped and, per current guideline recommendations, she was referred to surgical oncology for a wide local excision and sentinel lymph node biopsy. ${ }^{12}$ Negative margins were achieved and the results of the sentinel lymph node biopsy were negative. She is currently taking dimethyl fumarate (Tecfidera) for MS. To date, since stopping natalizumab, the patient has not presented with new skin lesions concerning for melanoma.

Case 2: A 37-year-old female with no prior history of skin cancer was given natalizumab for MS for 6 months before she developed several new melanocytic growths on her torso and bilateral lower extremities. Natalizumab was discontinued after 6 doses of therapy. Four months later, a melanoma was diagnosed on her back. Similar to Case 1, her treatment for MS was initially switched to Tecfidera. The patient has since undergone several changes in therapy and her disease continues to progress. To date, the patient has had no reports of new or changing nevi concerning for skin cancer.

\section{Literature review (Table 1)}

In addition to 2 cases from our skin oncology clinic, we found 193 reports of melanoma associated with natalizumab. $4,5,6$ 


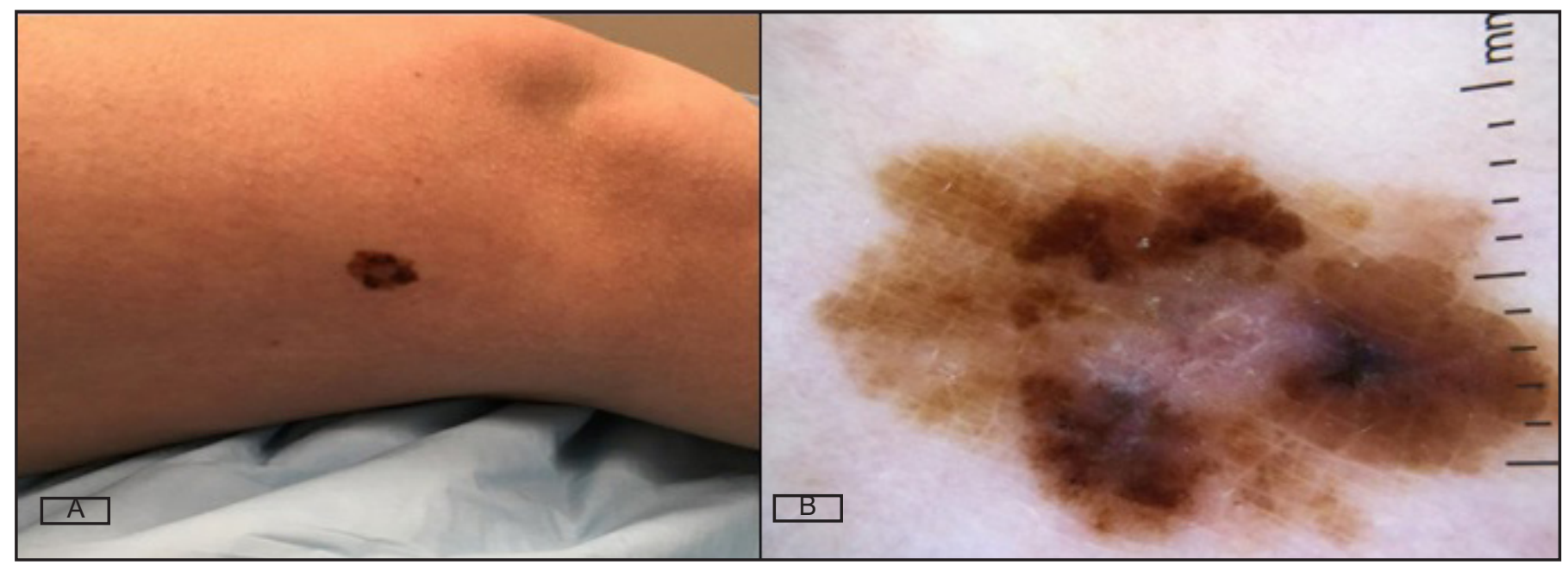

Figure 1. Melanocytic Growth in Patient Prescribed Natalizumab. (A) Clinical photo and (B) polarized dermoscopic image of $1.6 \mathrm{~cm}$ melanocytic growth on lateral aspect of right thigh

Sabol et al detailed an individual case report and included findings from both the FDA's Adverse Event Reporting System and their own literature search. The impetus behind their investigation stemmed from the development of a deadly urethral melanoma in a 43-year-old female with MS taking natalizumab for more than 2 years. Before April 1, 2014, there were 137 cases of natalizumabassociated melanomas reported to the Adverse Event Reporting System. An additional 45 cases were reported between April 1, 2014 and June 30, 2016. Of the cases reported up to April 2014, most were females being treated with natalizumab for MS. The median age at melanoma diagnosis was 45. Diagnosis was typically made within 2 years of natalizumab treatment. Most cases of natalizumabassociated melanoma were treated successfully with surgery. Nine patients $(6.6 \%)$ died from melanoma complications.

In the literature, Sabol et al found 7 additional cases of patients with MS who were taking natalizumab and developed melanoma, confirmed by biopsy. All but 1 case involved a female. The median age was 41 years, and the melanoma diagnosis occurred after a median of 12 doses of natalizumab. These 7 published cases include those reported by Vavricka et al and Mullen et al, which were part of our literature review.

Vavricka et al reported 1 case of a 41-year-old female with a history of atypical nevi who was taking natalizumab for MS for approximately 15 months. At this time, she developed a rapidly growing nevus on her upper arm that was later diagnosed as melanoma in situ and was excised successfully. Published by MaineHealth Knowledge Connection, 2021
Mullen et al wrote a letter to the editor of the New England Journal of Medicine highlighting 2 cases of natalizumab-associated melanoma in women in their mid-forties with a diagnosis of MS. One patient was a 46-year-old female who noticed a rapidly changing nevus on her shoulder shortly after taking her first dose of natalizumab. The biopsy revealed a thick, non-ulcerated melanoma with metastases to the lymph nodes. The second patient was a 45-yearold female who developed ocular melanoma from a longstanding ocular nevus after taking several doses of natalizumab.

\section{Innovative proposal}

We propose an innovative and proactive approach using TBP and SDDI before starting and while treating patients with natalizumab.

1. Before starting natalizumab, the patient should be seen by a dermatologist for a full-body skin examination with dermoscopy.

a. Lesions that are worrisome for melanoma should be either biopsied or further evaluated using RCM.

2. The patient should undergo baseline TBP with digital dermoscopic imaging.

3. The patient should be evaluated against baseline images every 4 to 6 months. New or changing growths should be biopsied.

We suspect our patients (and many of the reported cases) had tenuous melanocytic growths before starting natalizumab treatment, and the medication enabled the progression by adversely impacting 
Table 1. Literature Review of Case Reports of Natalizumab-Associated Melanomas

\begin{tabular}{|c|c|c|c|c|c|}
\hline Author & Age, y & Sex & $\begin{array}{l}\text { \# of doses at } \\
\text { melanoma } \\
\text { diagnosis }\end{array}$ & Clinical features & Other information \\
\hline \multirow{5}{*}{$\begin{array}{l}\text { Sabol et al } \\
(2017)\end{array}$} & 43 & $\mathrm{~F}$ & $\begin{array}{l}\text { Unknown } \\
\text { (estimated } 2.2 \text { y of } \\
\text { treatment) }\end{array}$ & $\begin{array}{l}\text { Polyp in distal urethra } \\
\text { positive for melanoma. }\end{array}$ & $\begin{array}{l}\text { Patient died from } \\
\text { widely metastatic } \\
\text { malignant urethral } \\
\text { melanoma. }\end{array}$ \\
\hline & 38 & M & 5 & -- & $\begin{array}{l}\text { Patient died from } \\
\text { melanoma. }\end{array}$ \\
\hline & 39 & $\mathrm{~F}$ & 5 & $\begin{array}{l}\text { After } 10 \text { months, ulcerated } \\
\text { and ablated. } 1.6 \mathrm{~mm} \\
\text { thickness and Clark level } \\
\text { IV. No metastasis to lymph } \\
\text { nodes. }\end{array}$ & $\begin{array}{l}\text { Therapy stopped after } \\
16 \text { doses. }\end{array}$ \\
\hline & 38 & $\mathrm{~F}$ & 77 & $\begin{array}{l}\text { Malignant melanoma. Clark } \\
\text { level III and Breslow index } \\
0.5 \mathrm{~mm} \text {. }\end{array}$ & $\begin{array}{l}\text { No evidence of } \\
\text { metastasis. }\end{array}$ \\
\hline & 48 & $\mathrm{~F}$ & 35 & $\begin{array}{l}5 \text { months after last dose, } \\
\text { noticed enlarging mole on } \\
\text { right shin. Lesion was flat } \\
\text { with a dark center. }\end{array}$ & $\begin{array}{l}\text { No evidence of } \\
\text { metastasis or } \\
\text { recurrence. }\end{array}$ \\
\hline $\begin{array}{l}\text { Sabol et } \\
\text { al (2017), } \\
\text { Vavricka et } \\
\text { al (2011) }\end{array}$ & 41 & $\mathrm{~F}$ & 12 & $\begin{array}{l}\text { Superficial spreading } \\
\text { melanoma from a dysplastic } \\
\text { nevus on upper arm. }\end{array}$ & $\begin{array}{l}\text { Had many atypical } \\
\text { moles for years. } \\
\text { Melanoma occurrence } \\
\text { close to therapy start. }\end{array}$ \\
\hline \multirow{2}{*}{$\begin{array}{l}\text { Sabol et } \\
\text { al (2017), } \\
\text { Mullen et al } \\
(2008)\end{array}$} & 46 & $\mathrm{~F}$ & 1 & $\begin{array}{l}\text { Mole on shoulder for a long } \\
\text { time before melanoma. } \\
\text { Had metastatic spread to } \\
\text { regional lymph nodes. }\end{array}$ & $\begin{array}{l}\text { After discontinuing } \\
\text { therapy, patient } \\
\text { developed widely } \\
\text { metastatic melanoma. }\end{array}$ \\
\hline & 45 & $\mathrm{~F}$ & Several & $\begin{array}{l}\text { Ocular melanoma. Long } \\
\text { history of mole in posterior } \\
\text { eye. Mole was unchanged } \\
\text { for } 6 \text { years before therapy. }\end{array}$ & $\begin{array}{l}\text { Family history of } \\
\text { melanoma. }\end{array}$ \\
\hline
\end{tabular}

\section{DISCUSSION}

The majority of melanomas diagnosed in patients taking natalizumab develop within approximately 2 years of beginning therapy, as was shown with Case $2 .{ }^{4}$ When melanoma is caught early, cure rates are nearly $100 \% .^{13}$ For patients prescribed natalizumab, https://knowledgeconnection.mainehealth.org/jmmc/vol3/iss $2 / 10$ current recommendations include a full-body skin examination conducted by a dermatologist every 6 months after starting treatment. ${ }^{4}$ However, given the mechanism of action of natalizumab, many of the melanomas diagnosed likely arose from preexisting melanocytic nevi, as seen in Case 1. 
immune surveillance. Thus, instead of waiting until a patient has already started treatment with natalizumab, we propose an innovative and proactive approach using TBP and SDDI. Much literature supports our assertion that TBP and SDDI will increase a dermatologist's ability to recognize new and preexisting skin lesions that have evolved since a patient began taking natalizumab. ${ }^{14,15,16,17}$ In patients over age $50,30 \%$ of new growths identified with TBP are melanoma. ${ }^{6}$ Furthermore, using TBP and SDDI, one study monitored 11,396 lesions on 629 patients at high risk for developing melanoma. ${ }^{14}$ A total of 98 melanomas ( $8.5 \%$ of excised lesions) were diagnosed in 78 patients (12.6\%). These lesions were identified at an early stage; 53 were superficial (in situ), 45 had a Breslow index (depth of tumor invasion) of $<1.0 \mathrm{~mm}$ (median $0.5 \mathrm{~mm}$ ), and all were without ulceration (presence of ulceration portends a higher risk for metastasis). ${ }^{14}$

\section{CONCLUSIONS}

Patients prescribed natalizumab have an increased risk for developing melanoma from new and preexisting skin lesions. Proactive TBP and SDDI using our innovative approach supports improved monitoring of melanocytic skin growths in a systematic, objective way that may detect melanoma at earlier stages in high-risk patients. For optimal outcomes, a partnership is essential between the neurologist who prescribes natalizumab and the dermatologist who monitors the skin.

Lastly, this brief report is timely. In October 2020, the Journal of the American Academy of Dermatology issued a statement encouraging dermatologists to use TBP with SDDI and RCM to aid in detecting skin melanoma. ${ }^{18}$ The skin oncology clinic at Maine Medical Partners offers all these cutting-edge technologies.

\section{Conflict of Interest: None}

\section{REFERENCES}

1. Hutchinson M. Natalizumab: a new treatment for relapsing remitting multiple sclerosis. Ther Clin RiskManag. 2007;3(2):259268. doi:10.2147/tcrm.2007.3.2.259

2. Elan Pharmaceuticals, Inc. Tysabri (natalizumab). Package insert. U.S. Food and Drug Administration. Updated January 2012. Accessed November 13, 2020. https://www.accessdata.fda.gov/ drugsatfda_docs/ label/2012/125104s0576lbl.pdf
3. Conway DS, Hersh CM, Harris HC, Hua LH. Duration of natalizumab therapy and reasons for discontinuation in a multiple sclerosis population. Mult Scler J Exp Transl Clin. 2020;6(1):2055217320902488. doi:10.1177/2055217320902488

4. Sabol RA, Noxon V, Sartor O, et al. Melanoma complicating treatment with natalizumab for multiple sclerosis: a report from the Southern Network on Adverse Reactions (SONAR). Cancer Med. 2017;6(7):1541-1551. doi:10.1002/cam4.1098

5. Prinz Vavricka BM, Baumberger P, Russmann S, KullakUblick GA. Diagnosis of melanoma under concomitant natalizumab therapy. Mult Scler. 2011;17(2):255-256. doi:10.1177/1352458510389629

6. Mullen JT, Vartanian TK, Atkins MB. Melanoma complicating treatment with natalizumab for multiple sclerosis. $N$ Engl J Med. 2008;358(6):647-648. doi:10.1056/NEJMc0706103

7. Gandoglia I, Ivaldi F, Carrega P, et al. In vitro VLA-4 blockade results in an impaired NK cell-mediated immune surveillance against melanoma. Immunol Lett. 2017;181:109-115. doi:10.1016/j.imlet.2016.11.015

8. Carbone ML, Lacal PM, Messinese S, et al. Multiple Sclerosis Treatment and Melanoma Development. Int $J$ Mol Sci. 2020;21(8):2950. doi:10.3390/ijms21082950.

9. FotoFinder Systems I. Screening examinations with state-ofthe-art technology. Accessed January 10, 2021. https://www. fotofinder-systems.com/patient-information/

10. Stanganelli I. Dermoscopy. Medscape. Updated March 13, 2018. Accessed January 10, 2021. https://emedicine.medscape.com/ article/ 1130783-overview

11. Tromme I, Devleesschauwer B, Beutels P, et al. Selective use of sequential digital dermoscopy imaging allows a cost reduction in the melanoma detection process: a Belgian study of patients with a single or a small number of atypical nevi. PLoS One. 2014;9(10):e109339. doi:10.1371/journal.pone.0109339

12. Swetter SM, Tsao H, Bichakjian CK, et al. Guidelines of care for the management of primary cutaneous melanoma. $\mathrm{J} \mathrm{Am} \mathrm{Acad}$ Dermatol. 2019;80(1):208-250. doi:10.1016/j.jaad.2018.08.055

13. Melanoma Survival Rates. Melanoma Research Alliance. Accessed June 25, 2019. https://www.curemelanoma.org/aboutmelanoma/melanoma-staging/melanoma-survival-rates/

14. Salerni G, Carrera C, Lovatto L, et al. Benefits of total body photography and digital dermatoscopy ("two-step method of digital follow-up") in the early diagnosis of melanoma in patients at high risk for melanoma. J Am Acad Dermatol. 2012;67(1):e17-e27. doi:10.1016/j.jaad.2011.04.008

15. Wang SQ, Kopf AW, Koenig K, Polsky D, Nudel K, Bart RS. Detection of melanomas in patients followed up with total cutaneous examinations, total cutaneous photography, and dermoscopy. J Am Acad Dermatol. 2004;50(1):15-20. doi:10.1016/s0190-9622(03)02794-4

16. Banky JP, Kelly JW, English DR, Yeatman JM, Dowling JP. Incidence of new and changed nevi and melanomas detected using baseline images and dermoscopy in patients at high risk for melanoma. Arch Dermatol. 2005;141(8):998-1006. doi:10.1001/ archderm.141.8.998

17. Feit NE, Dusza SW, Marghoob AA. Melanomas detected with the aid of total cutaneous photography. $\mathrm{Br} J$ Dermatol. 2004;150(4):706-714. doi:10.1111/j.0007-0963.2004.05892.x

18. Fried L, Tan A, Bajaj S, Liebman TN, Polsky D, Stein JA. Technological advances for the detection of melanoma: advances in diagnostic techniques. J Am Acad Dermatol. 2020;83(4):983992. doi:10.1016/j.jaad.2020.03.121 